\title{
Experimental Investigation into Limit Void Ratio Characteristics of Calcareous Sands considering Various Factors
}

\author{
Baojian Li $\mathbb{D}^{1},{ }^{1}$ Gang Lei $\left(\mathbb{D},{ }^{1,2}\right.$ Panpan Guo $\mathbb{D},{ }^{1}$ Gaoyun Zhou, $^{1}$ Zhe Wang, $^{3}$ \\ and Xiaonan Gong \\ ${ }^{1}$ Research Center of Coastal and Urban Geotechnical Engineering, Zhejiang University, Hangzhou 310058, China \\ ${ }^{2}$ Beijing Urban Construction Design \& Development Group Company Limited, Beijing 100037, China \\ ${ }^{3}$ College of Civil Engineering and Architecture, Zhejiang University of Technology, Hangzhou 310023, China
}

Correspondence should be addressed to Gang Lei; 11812105@zju.edu.cn

Received 14 May 2021; Accepted 15 June 2021; Published 25 June 2021

Academic Editor: Yu Wang

Copyright (C) 2021 Baojian Li et al. This is an open access article distributed under the Creative Commons Attribution License, which permits unrestricted use, distribution, and reproduction in any medium, provided the original work is properly cited.

\begin{abstract}
Relative density is an important index affecting the mechanical behaviors of calcareous sands. The dense sands present softening strength, whereas the loose sands exhibit hardening strength. Furthermore, the relative density is determined based on the maximum and minimum void ratios obtained by using the maximum and minimum dry density test. In this study, a series of tests were carried out on various mixed graded sands to explore their material properties and the relationship between the limit void ratio, considering the effects of test methods, equipment, and fine content. It is shown that a more accurate maximum void ratio can be attained by using the $1000 \mathrm{~mL}$ measuring cylinder with low rotation speed. In addition, in order to avoid particle breakage of calcareous sands, it is suggested that the minimum void ratio should be obtained with the $1000 \mathrm{~mL}$ compaction cylinder combining vibration with hit. The results also show that a linear relationship exists among the limit void ratio of various mixed graded sands. Besides, the void ratio is significantly affected by the fine content. $40 \%$ is the critical fine content corresponding to the lowest value of the limit void ratio.
\end{abstract}

\section{Introduction}

Calcareous sands are special soils, which are biogenic sediments and skeletal remains of marine organisms. The main composition is calcium carbonate with a lower hardness than silica sands [1-6]. They are widely distributed in shallow, warm, and continental shelf seas. Calcareous sands are characterized by high crushability, irregular particle shape, high intraparticle void, and complex microstructure. Therefore, their mechanical behaviors are quite different from that of terrigenous sands [7-10]. With the implementation of the Belt and Road Initiative, calcareous sands have been a topic of interest among geotechnical researchers recently. However, they tend to concern particle shape and breakage [11-13], biocementation [14-16], and bearing capacity of pile foundations [17-19]. There are few papers on maximum and minimum void ratios and relative density of calcareous sands.

Relative density, $D_{\mathrm{r}}$, is a crucial indicator reflecting the compactness of noncohesive soil, which has been proposed and widely used by domestic and foreign scholars since the 1940s [20]. It is a state parameter indicating how dense a given sand sample or deposit is with respect to its range of possible densities. It has a governing influence on strength and stability of sand in filling engineering, such as embankment, retaining wall, and ground improvement [21-23]. Nevertheless, the determination of the maximum and minimum void ratios is the prerequisite for calculating the relative density. Two parameters, $e_{\min }$ and $e_{\max }$, cannot be directly measured and must be determined by the maximum and minimum dry densities of sand. Generally, the minimum dry density $\rho_{\mathrm{dmin}}$ is often measured by the funnel methods 


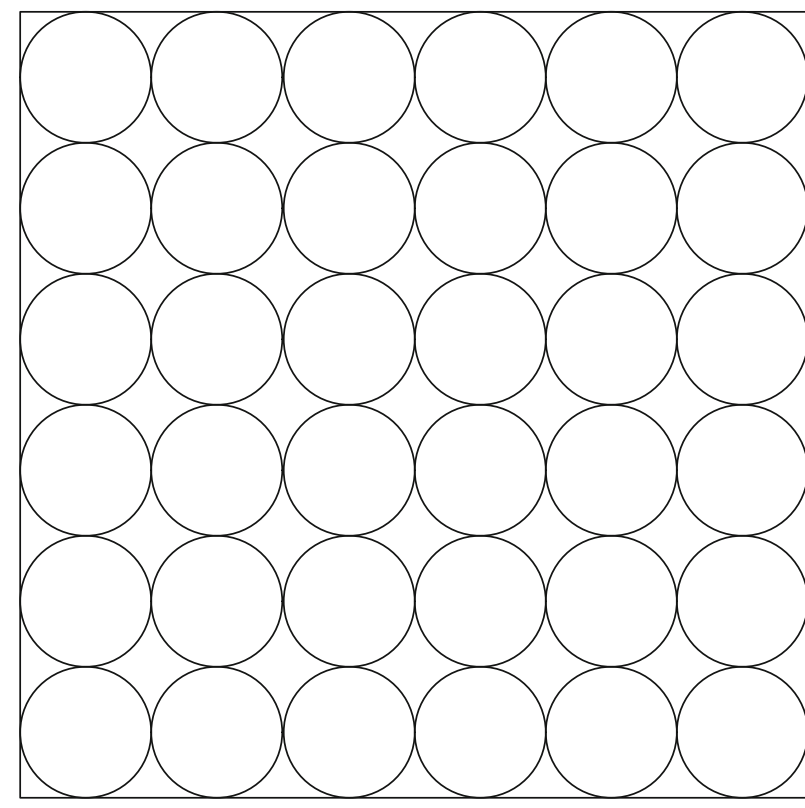

(a)

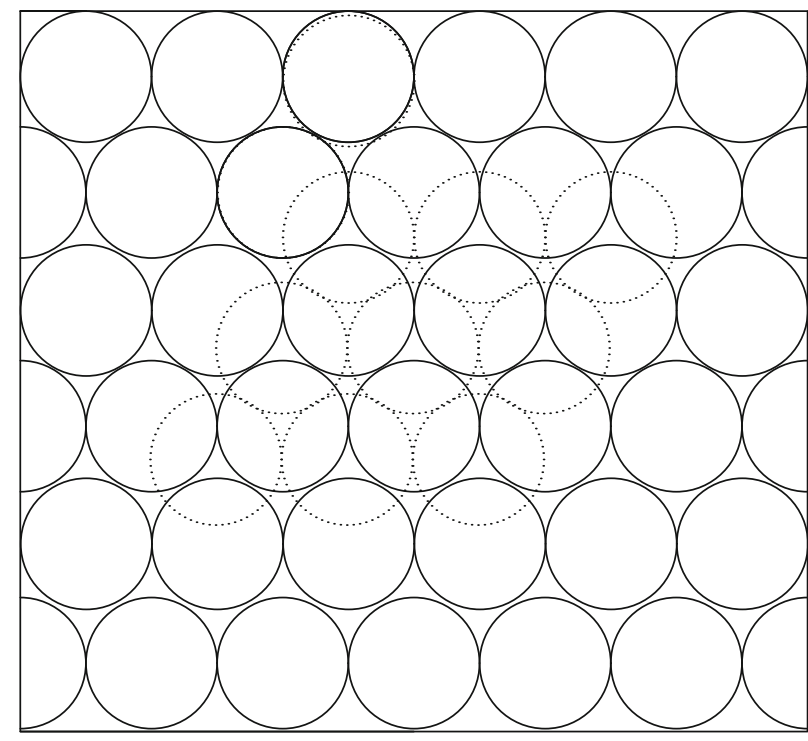

(b)

Figure 1: Schematic illustration of packing of single-size spheres: (a) loosest state and (b) densest state.

or the measuring cylinder method, and the maximum dry density $\rho_{\mathrm{dmax}}$ is usually measured by the vibration-hammer method [24, 25].

Experimental research shows that the main factors affecting the maximum and minimum dry densities of sand are particle shape, uniformity coefficient, fine content, instrument size, test method, and so on. The formula for calculating the maximum and minimum dry densities of noncohesive soil is proposed, considering compaction power, particle composition and shape, and particle filling [26-28]. Unfortunately, the result is far from satisfactory, because of idealized assumptions. Meanwhile, some improved methods are found to measure the maximum and minimum dry densities of terrigenous sands $[29,30]$. Previous researches mainly focus on clean sand. In particular, characteristics of $e_{\max }$ and $e_{\min }$ have been studied in the context of applicability and accuracy of the relative density. Other studies have investigated the relation between the material properties and $e_{\max }$ or $e_{\min }$ of sand. Recently, effects of fines on the limit void ratio $\left(e_{\max }\right.$ and $\left.e_{\min }\right)$ have been a new theme to examine the influence of fines on the physical and mechanical properties of quartz sands among geotechnical scholars [31-34]. A large number of test data on silty sand were examined, and a set of empirical equations were proposed to show the effect of fine content on the minimum void ratio [35]. Apart from these studies, computer simulation analyses using the discrete element method have also been carried out to study the characteristics of the limit void ratio of particle mixtures. The trend of computer simulation results resembles that obtained from experimental tests [36-38].

Above all, compared to the number of studies on mechanical behaviors of calcareous sands and influence factors of relative density, the impact on the relative density of test methods and fine content of calcareous sands is rather limited. In the present study, we aim to examine the void ratio characteristics for calcareous sands including clean sands and sands containing a small amount of fine-size particles (diameter $<0.075 \mathrm{~mm}$ ). Specifically, the study highlights the influence of test methods and equipment on $e_{\max }, e_{\min }$, and $D_{\mathrm{r}}$. In what follows, binary relationships between the maximum and minimum void ratios are obtained. The results supplement the relevant provisions of the national regulations, which can improve the availability of the laboratory test.

\section{Idealized Packing of Spherical Grains}

Analyzing the idealized packing of spherical grains is an effective way to understand the characteristics of soil. At the same time, it is suitable for sand to build the physical model based on spherical particles [39-43]. For convenience, in theoretical calculation, it was assumed that the sand particle is completely incompressible.

2.1. Single-Size Spheres. For single-size spheres, the loosest possible packing is shown in Figure 1(a), with the corresponding maximum void ratio being calculated according to the following equations:

$$
\begin{aligned}
V & =6 D \times 6 D \times D=36 D^{3}, \\
V_{\mathrm{s}} & =6 \times 6 \times \frac{4}{3} \pi\left(\frac{D}{2}\right)^{3}=6 \pi D^{3} \approx 18.85 D^{3}, \\
V_{\mathrm{v}} & =V-V_{\mathrm{s}} \approx 17.15 D^{3}, \\
e_{\max } & =\frac{V_{\mathrm{v}}}{V_{\mathrm{s}}}=0.9098,
\end{aligned}
$$

where $D$ is the diameter of sand particles and $V, V_{s}$, and $V_{\mathrm{v}}$ are the volume of sand, sand particles, and void. 


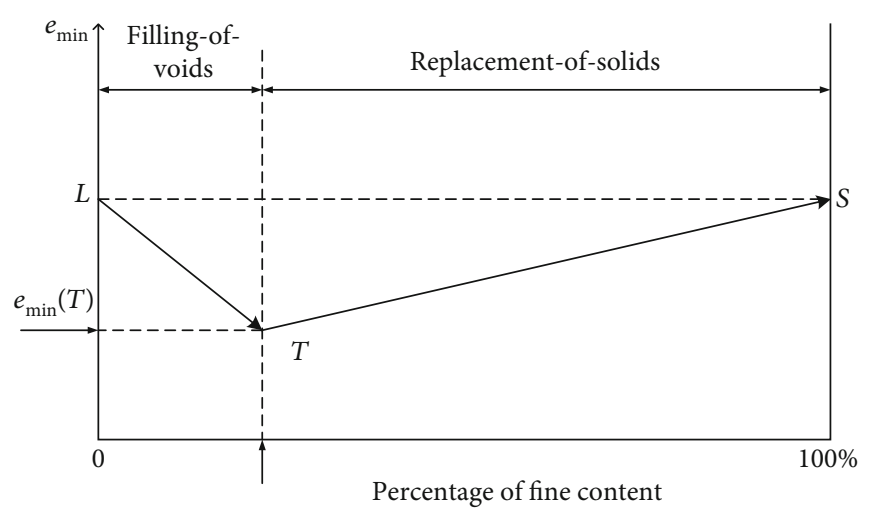

FIgURE 2: Effect of fines on binary packing of spherical particles in $e_{\min }$.

On the other hand, Figure 1(b) displays the void ratio of densest packing. The volume of sand is composed of 3 parts: $V_{\mathrm{s} 1}=$ the volume of complete sphere particles, $V_{\mathrm{s} 2}=$ the volume of sand embedded in the pores above the first layer and below the sixth layer, and $V_{s 3}=$ the volume of sand embedded in the pores among three balls between the upper and lower sides. The minimum void ratio is computed by Equations (2)-(8). It is obvious from the above results that the maximum and minimum void ratios are independent of the size in the certain number of idealized single-sized spheres:

$$
\begin{aligned}
V= & 6 D \times\left(\frac{5 \sqrt{3}}{2}+1\right) D \times D=31.98 D^{3}, \\
V_{\mathrm{s} 1}= & 6 \times 6 \times \frac{4}{3} \pi\left(\frac{D}{2}\right)^{3}=6 \pi D^{3} \approx 18.85 D^{3}, \\
V_{\mathrm{s} 2}= & 12 \times V_{\mathrm{s} 2}{ }^{\prime}=12 \times \frac{1}{4} \\
& \times\left\{\frac{\pi}{6} D^{3}-\left[\left(\frac{\sqrt{3} D}{2}-\frac{D}{2}\right) \times 2\right]^{3}\right\} \\
\approx & 0.384 D^{3}, \\
V_{\mathrm{s} 3}= & 120 \times V_{\mathrm{s} 3}{ }^{\prime}=120 \\
& \times\left[\frac{\pi}{36} D^{3}-\frac{1}{3} \times 0.471 \times\left(\frac{\sqrt{6}}{3}-\frac{1}{2}\right) D^{3}\right] \\
\approx & 4.51 D^{3}, \\
V_{\mathrm{s}}= & V_{\mathrm{s} 1}+V_{\mathrm{s} 2}+V_{\mathrm{s} 3}=23.74 D^{3}, \\
V_{\mathrm{v}}= & V-V_{\mathrm{s}}=8.24 D^{3}, \\
e_{\min }= & \frac{V_{\mathrm{v}}}{V_{\mathrm{s}}}=0.347 .
\end{aligned}
$$

2.2. Mixtures of Two Grain Sizes. When mixing two spherical particles of different sizes, the packing is influenced by the proportion of large and small particles in the total volume of solids as well as by the relative sizes of the large and small spheres. Figure 2 schematically shows the corresponding change in $e_{\min }$ with the percentage of fine content.

The point $L$ expresses the densest packing of the larger spherical particles. At first, adding smaller-size spheres to the densest packing of large spheres results in a decrease in the volume of void for small particles fill in the void among the large particles, which is denoted the filling-of-voids process with the path $L-T$ in the diagram. When the content of small spheres exceeds the threshold percentage corresponding to point $T$, a reverse trend is evident in which the volume of void increases with the percentage of the small-size content. Subsequently, in the so-called replacement-of-solids phase, the large-size spheres are separated and increasingly replaced by the small-size particles until the solid is composed of the smaller particles (point $S$ ). So, we can see that $e_{\min }$ decreases during the filling-of-voids phase and reaches its minimum value at a certain percentage $T$. Then, $e_{\min }$ steadily increases in the course of the replacement-of-solids phase, with the path $T$-S. In practice, the value of $e_{\min (L)}$ is similar to that of $e_{\min (S)}$ since the voids have no concern with the size of spherical particles.

Obviously, $e_{\max }$ of mixtures of two grain sizes may change with the fine content similar to $e_{\min }$ in Figure 2. But the value may be nearly constant or slightly increase with an addition of a very small amount of fines because the small particles do not fill the void formed by the large spheres yet.

\section{Materials and Methods}

3.1. Experimental Materials. The sand samples as shown in Figure 3 are biogenic sediments and skeletal remains of marine organisms retrieved from the reef reclamation site in Nansha Island, South China Sea. The total area of coral reef in the South China Sea is about $3.8 \times 10^{4} \mathrm{~km}^{2}$, accounting for $5 \%$ of the total amount all around the world [44]. Most of the coral reef is located in the region of Nansha Island in our country. Figure 4 displays the grain size distribution curve of calcareous sands collected from Nansha Island. A natural grading with grain diameter less than 5.0 $\mathrm{mm}$ was retained for the test. The physical parameters are shown in Table 1. According to the characteristics of particle sizes, the investigated materials include coarse and medium 


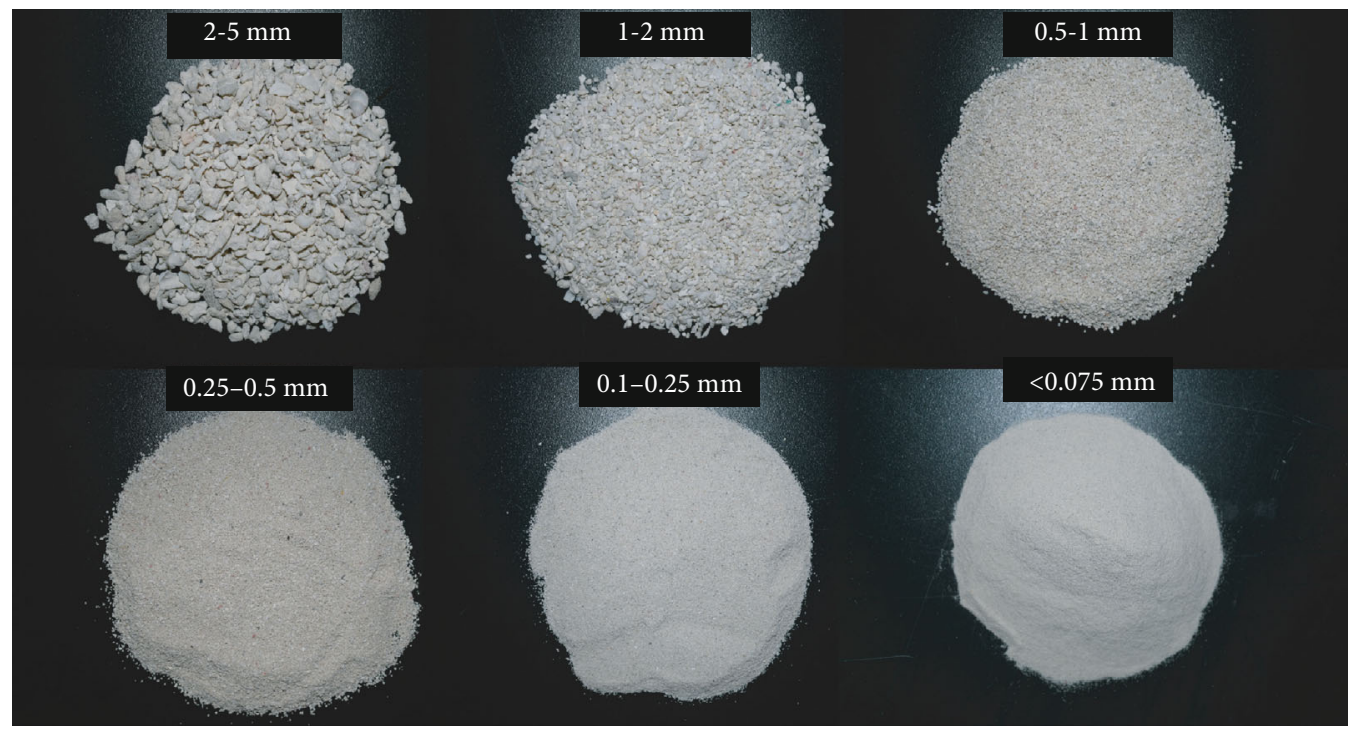

Figure 3: Sand samples of different grain sizes.

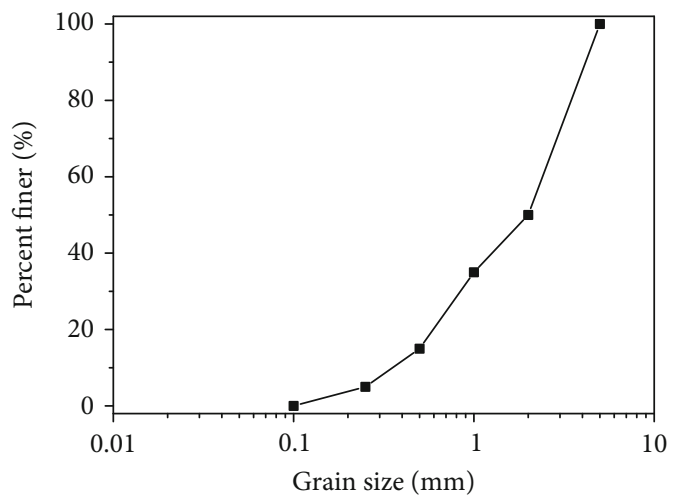

FIGURE 4: Grain size distribution curves of calcareous sands.

TABLE 1: Physical properties of calcareous sands.

\begin{tabular}{lccccc}
\hline$G_{\mathrm{S}}$ & $d_{60}(\mathrm{~mm})$ & $d_{30}(\mathrm{~mm})$ & $d_{10}(\mathrm{~mm})$ & $C_{\mathrm{u}}$ & $C_{\mathrm{c}}$ \\
\hline 2.79 & 2.60 & 0.88 & 0.38 & 6.84 & 0.78 \\
\hline
\end{tabular}

Note. $G_{\mathrm{S}}=$ specific gravity; $d_{60}=$ limited particle size; $d_{30}=$ median particle size; $d_{10}=$ effective particle size; $C_{\mathrm{u}}=$ coefficient of uniformity; $C_{\mathrm{c}}=$ coefficient of curvature.

sand without fine particles. The main reasons are sampling location and construction characteristics of hydraulic filling. In the process of reef reclamation, under the action of hydraulic screening and particle gravity, the coarse sand particle tends to accumulate near the mouth of the reclamation site, while the fine particle tends to accumulate downstream with the flow of water, resulting in the uneven distribution. The sand sample used in this experiment was taken from the shallow surface upstream. Therefore, it is poor distribution without particles below $0.1 \mathrm{~mm}$.

3.2. The Minimum and Maximum Dry Density Test. As is mentioned above, relative density is an important parameter of sand, which is analyzed by Equation (9). Nevertheless, the limit void ratio is difficult to measure directly and needs to be computed using Equations (10) and (11). Namely, relative density can be obtained by measuring the maximum and minimum dry densities:

$$
\begin{aligned}
D_{r} & =\frac{e_{\max }-e}{e_{\max }-e_{\min }}, \\
e_{\max } & =\frac{\rho_{\mathrm{w}} G_{\mathrm{s}}}{\rho_{\mathrm{d} \min }}-1, \\
e_{\min } & =\frac{\rho_{\mathrm{w}} G_{\mathrm{s}}}{\rho_{\mathrm{d} \max }}-1,
\end{aligned}
$$

where $\rho_{\mathrm{w}}$ is the density of water $\left(\mathrm{kg} / \mathrm{m}^{3}\right), \rho_{\mathrm{dmin}}$ is minimum dry density, and $\rho_{\mathrm{dmax}}$ is maximum dry density.

The standard [24] suggests that the minimum dry density should be obtained by the funnel method or the measuring cylinder method. The volume of the measuring cylinder is $500 \mathrm{~mL}$ or $1000 \mathrm{~mL}$, and the mass of sand samples is $700 \mathrm{~g}$. In order to study the influence of the volume of measuring cylinder and test methods on the minimum dry density, 3 different volume ranges $(250,500$, and $1000 \mathrm{~mL}$ ) were used in the experiment. The sand samples were experimented with by the funnel method $\left(\mathrm{M}_{1}\right)$, fast measuring cylinder method $\left(\mathrm{M}_{2}\right)$, and slow measuring cylinder method $\left(\mathrm{M}_{3}\right)$. The speed of sand falling into the measuring cylinders through funnels was approximately $5 \mathrm{~g} / \mathrm{s}$. The inversion speeds of measuring cylinders in $\mathrm{M}_{2}$ and $\mathrm{M}_{3}$ were, respectively, $30 \mathrm{~s} / 180^{\circ}$ and 60 $\mathrm{s} / 180^{\circ}$. Each group of tests was repeated 3 times, and the average value was taken as the final results.

On the other hand, for the determination of maximum dry density, there is no internationally uniform method. China geotechnical engineers often use the vibrationhammer method. During the test, the sand samples were compacted and hammered to obtain the idealized maximum dry density. In order to analyze the influence of test equipment on maximum dry density, the compaction cylinder 


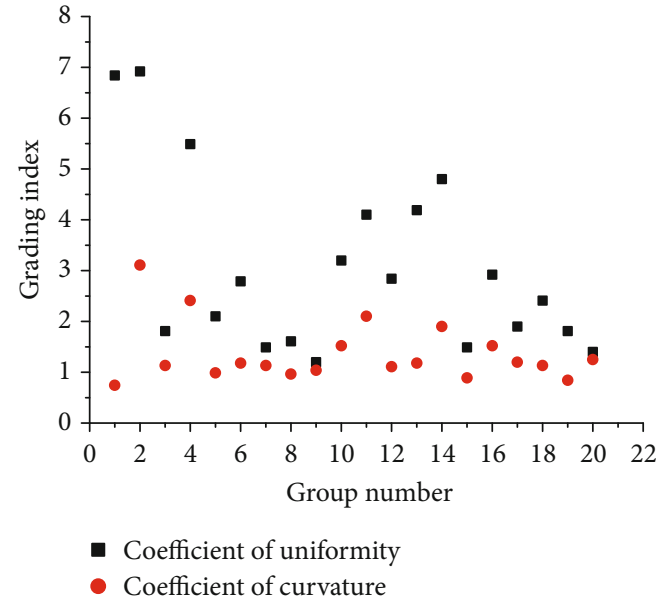

FIGURE 5: Grading indexes of experimental sands.

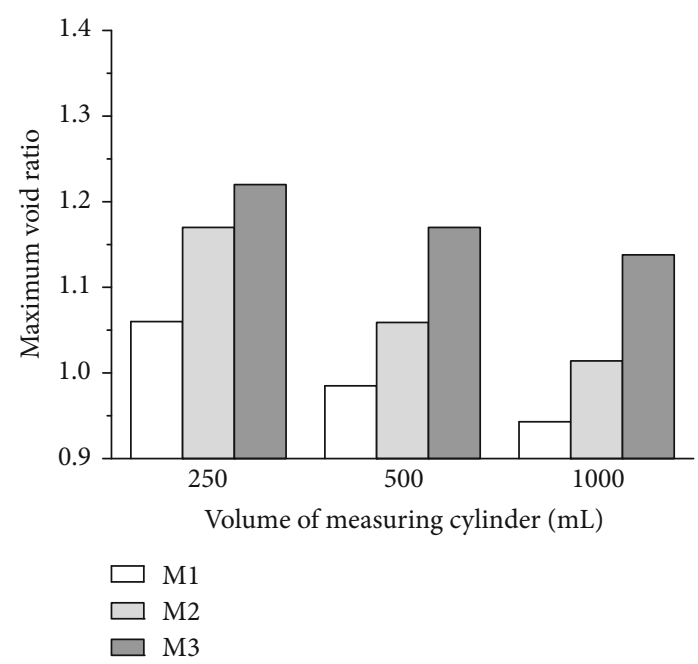

FIGURE 6: Maximum void ratio in different volumes of measuring cylinder.

with a volume of 250 and $1000 \mathrm{~mL}$ was selected for layered compaction. When sand samples reached a constant value, the mass was weighed and the corresponding maximum dry density was calculated. Similarly, every experiment was conducted 3 times, and the average value was considered the final results.

3.3. Test on the Relationship between the Maximum and Minimum Void Ratios. It is well known that maximum and minimum void ratios of sand are evaluated from laboratory tests through two independent test methods for the minimum and maximum dry densities, respectively. But previous studies have reported that a linear correlation was derived to express the relationship between $e_{\max }$ and $e_{\min }$ of terrigenous sands [45]. For the sake of exploring the relationship of calcareous sands, the experimental sand samples of various distributions were mixed at random. 20 groups of sand with diverse grading indexes shown in Figure 5 were configured.

3.4. Test on the Influence of Fine Content on the Limit Void Ratio. Fine contents are a critical factor affecting the void ratio of sand. For a further study, calcareous sands were mixed with $10 \%, 20 \%, 30 \%, 40 \%, 50 \%, 60 \%, 70 \%, 80 \%$, $90 \%$, and $100 \%$ of fine particles to produce 10 groups with diverse grain compositions. The following was determining the minimum and maximum dry densities and computing the limit void ratio. Before the test, sand was washed with clean water to remove fine and clay particles on the surface and in the inner pore of large particles.

\section{Results and Discussion}

4.1. The Effects of Test Methods and Equipment on Maximum and Minimum Void Ratios. Before exploring the maximum and minimum void ratios of sand, it is necessary to address several important issues related to the determination procedures and applicability of minimum and maximum dry densities. According to the funnel method and measuring cylinder method to estimate minimum dry density of calcareous sands, the maximum void ratio was acquired. The results in Figure 6 indicate that the value of the funnel method was the largest, followed by the fast measuring cylinder method, and the slow measuring cylinder method was the smallest in the same volume of measuring cylinder. What is more, the larger the volume, the smaller the void ratio in the similar test method.

It can also be seen that the void ratio measured by the funnel method $\left(\mathrm{M}_{1}\right)$ was smaller than that of the measuring cylinder methods $\left(\mathrm{M}_{2}\right.$ and $\left.\mathrm{M}_{3}\right)$, which was caused by the different determination operations. In the process of $M_{1}$, since the particles dropping from the funnel had a certain falling speed, the void between particles and between the particles and measuring cylinder was small. In particular, due to the limitation of the funnel size, the given large particles almost slowly fall one by one, leading to a tight sand sample. For $\mathrm{M}_{3}$, the entire operation being carried out slowly, it only changed the relative position of particles inside the samples. The void was more than that measured by $M_{1}$. Besides, different volumes of measuring cylinders had a certain impact on the experimental results. When the volume was smaller, sand particles were more likely to be arranged in layers, which made a higher value of the maximum void ratio. Therefore, we should choose the slow measuring cylinder method and a large volume of measuring cylinder to evaluate the minimum void ratio in the laboratory test. Strangely, the idealized value of the maximum void ratio was unexpectedly lower than the measured one. The main reason is that the natural sand particles are not regular spherical, and there are arching and cavitation inside them during determination procedures. And particles of calcareous sands are rich in the inner pore, displayed in Figure 7 (50 and 2000 magnification times, respectively), simultaneously resulting in the peculiar phenomenon.

Table 2 presents the maximum dry density and minimum void ratio of sand measured by the vibratory hammer method using a compaction cylinder with a volume of 250 and $1000 \mathrm{~mL}$. It is found that under the same condition, the measured minimum void ratio with a volume of $250 \mathrm{~mL}$ is significantly lower than that of the $1000 \mathrm{~mL}$ compaction cylinder. 

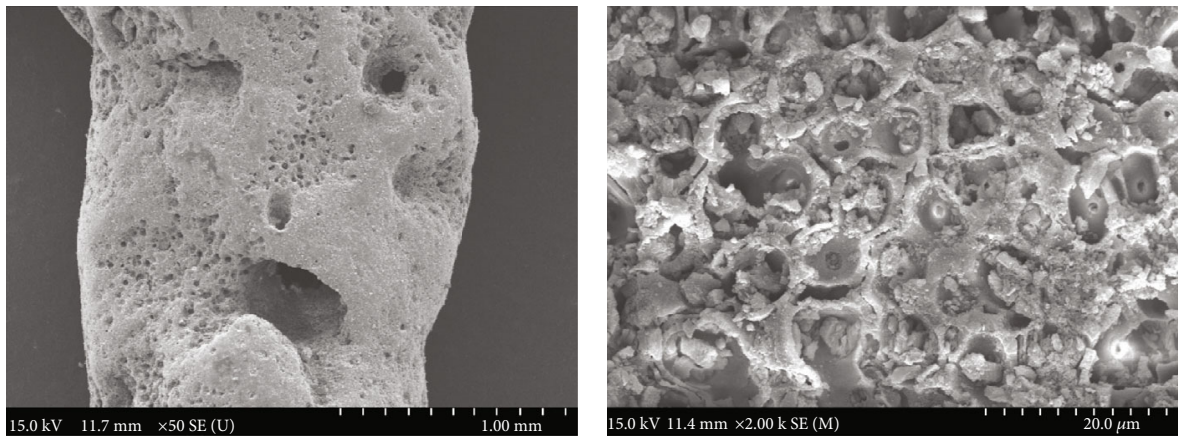

Figure 7: SEM scanning images of calcareous sands.

TABle 2: Maximum dry density and minimum void ratio under the volume of 250 and $1000 \mathrm{~mL}$.

\begin{tabular}{lccccc}
\hline$V(\mathrm{~mL})$ & $m_{\mathrm{s}}(\mathrm{g})$ & $\rho_{\mathrm{d} \max }\left(\mathrm{g} / \mathrm{cm}^{3}\right)$ & $\rho_{\mathrm{d} \max }^{\prime}\left(\mathrm{g} / \mathrm{cm}^{3}\right)$ & $e_{\min }$ & $e_{\min (\mathrm{I})}$ \\
\hline \multirow{2}{*}{250} & 389.5 & 1.558 & & & \\
& 392.5 & 1.570 & 1.561 & 0.78 & \\
& 388.7 & 1.555 & & & 0.347 \\
1000 & 1503.2 & 1.503 & & & \\
& 1485.1 & 1.485 & 1.493 & 0.87 & \\
& 1491.4 & 1.491 & & & \\
\hline
\end{tabular}

Note. $V=$ volume of compaction cylinder; $m_{\mathrm{s}}=$ mass of sand; $\rho_{\mathrm{dmax}}^{\prime}=$ average value of maximum dry density; $e_{\min (\mathrm{I})}=$ minimum void ratio of idealized single-size spheres.

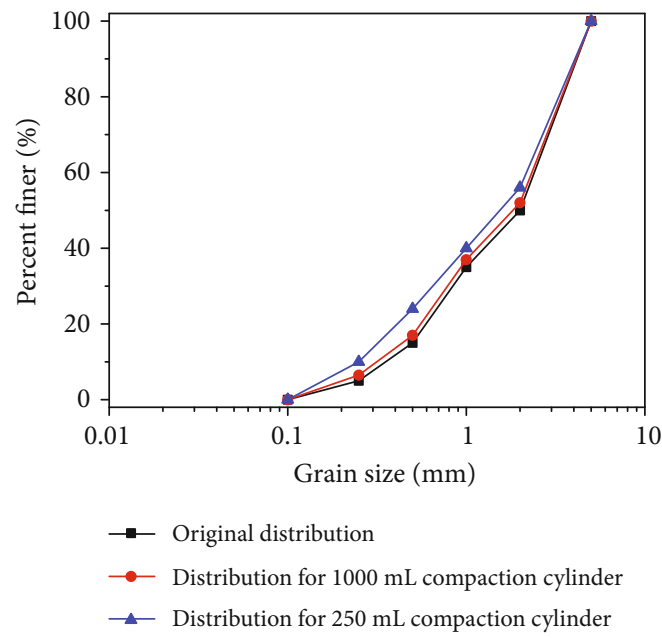

FIgURE 8: Grain size distribution curves for 250 and $1000 \mathrm{~mL}$ compaction cylinders.

The grain size distribution curves of calcareous sands before and after vibration hammering are shown in Figure 8 . For the $250 \mathrm{~mL}$ compaction cylinder, due to the small inner diameter, the compaction energy was more likely to accumulate, making the coarse particles easy to break, which resulted in an increase in the maximum dry density and a decrease in the minimum void ratio. Compaction energy had a significant effect on the crushing of medium and coarse particles. However, the grading curve did not change significantly after being hammered in a compaction cylinder with a volume of $1000 \mathrm{~mL}$. So, for the vibrationhammer method to determine the maximum dry density of sand, in order to be more similar to the given graded sand, it is recommended that a $1000 \mathrm{~mL}$ compaction cylinder should be used. In addition, compared with the idealized minimum void ratio, the experimental value converted from the test on maximum dry density was different from the theoretical one. This is because the premise of theoretical calculation is that the sand particles are assumed to have a uniform sphere. The shape of actual sand particles is irregular, and the arrangement is also different.

In summary, the maximum and minimum void ratios of a given sandy soil are not unique, but rather, they rest with the test methods and equipment used to determine them. For this reason, when comparing the limit void ratio of various soils, it is an essential and prerequisite condition that $e_{\max }$ or $e_{\min }$ of all soils are measured using the same test procedures (including methods, equipment, and experimental steps) for $\rho_{\mathrm{dmin}}$ or $\rho_{\mathrm{dmax}}$, respectively. Although these procedures tend to identify the limited dry density of given sand, it would be difficult to determine the minimum and maximum densities in the true sense.

\subsection{A Linear Relationship between Maximum and Minimum} Void Ratios. The maximum and minimum dry density test was carried out on these 20 groups of sands. Even though the limit void ratio was obtained from two independent tests that have opposite targets, namely, to produce the loosest state and the densest state of a sand sample, respectively, yet Figure 9 indicates that there is a linear relationship between $e_{\max }$ and $e_{\min }$ of the compiled sands evidently. However, when the value of $e_{\min }$ was in a lower range of 0.6 to 0.75 , the distribution of $e_{\max }$ was relatively discrete, which made the linear relationship between the maximum and minimum void ratios a little weaker. As the range of $e_{\min }$ increases, $e_{\max }$ of the sand samples became a more and more well-defined relationship. This is consistent with the results of Cubrinovski and Ishihara, Yilmaz, and Muszynaki [35, $41,46]$.

4.3. Discussion on Influence of Fine Content on Limit Void Ratio. For each type of composite sands, the maximum and minimum void ratios have been determined according to the above laboratory procedures. Therefore, it is possible to plot the values of $e_{\max }$ and $e_{\min }$ as a function of the fine 


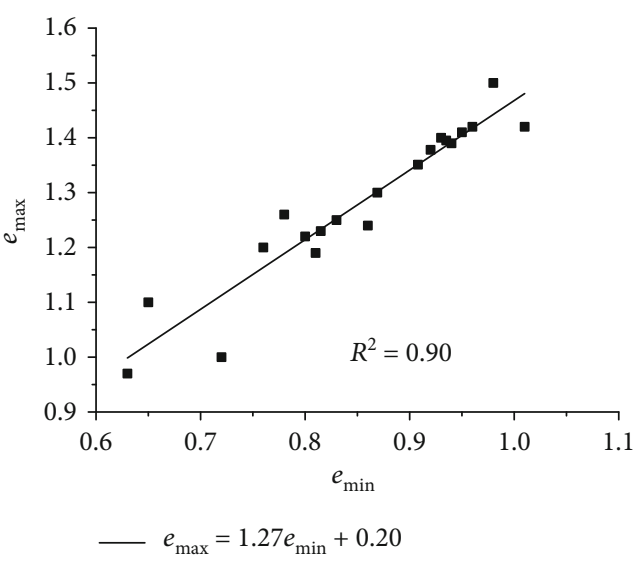

FIgURE 9: Correlation between $e_{\max }$ and $e_{\min }$ of calcareous sands.

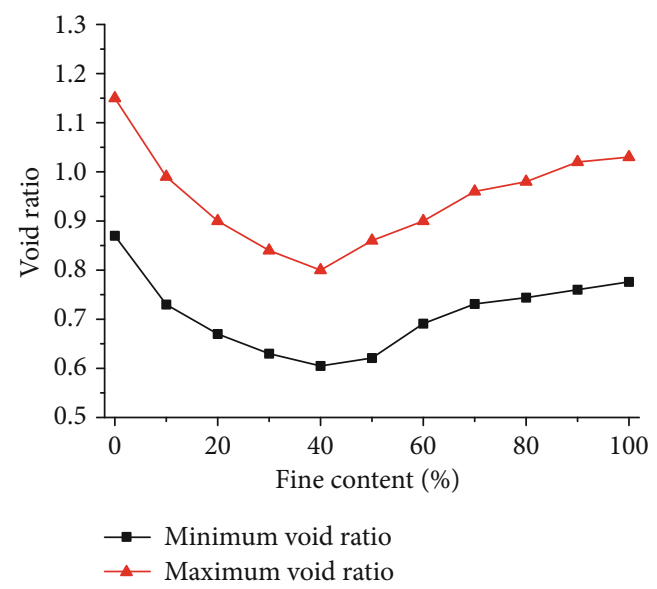

Figure 10: Variation in $e_{\max }$ and $e_{\min }$ with fine content.

content for each of the composite soils, as shown in Figure 10. It is observed that both $e_{\max }$ and $e_{\min }$ initially decreased as the fine content increased from $0 \%$ to about $30 \%$. Within the range of 30 to $50 \%$ fines, the correlations presented a change of form indicating a transition from the filling-of-voids to the replacement-of-solids process. Above $60 \%$ fines, the maximum and minimum void ratios were seen to steadily increase until they eventually reached $100 \%$ fine content. It is indicated that the variation of $e_{\max }$ and $e_{\min }$ with the fine content in Figure 10 closely resembled that of the spherical particles shown in Figure 2. But $e_{\max }$ and $e_{\min }$ of the nature sands without fines were higher than that with $100 \%$ fine content, which differed from the idealized values and previous studies [47]. Maybe there are 2 main reasons. On the one hand, the original sands are full of void among particles, leading to poor distribution. Besides, compared with fine fractions, the nature sands without fines are rich in intraparticle voids.

\section{Conclusions}

A series of data were acquired by the maximum and minimum dry density test on various mixed sand. The main conclusions drawn from this study can be summarized as follows.
(1) The maximum and minimum dry density test should adopt the vibration-hammer method and slow measuring cylinder methods, respectively. To avoid the influence of equipment on experimental results, measuring cylinder and compaction cylinder with a volume of $1000 \mathrm{~mL}$ should be used

(2) An almost linear relationship exists between the maximum and minimum void ratios of various mixed graded sand. The relationship has a high correlation coefficient of 0.9 and can be used to approximately evaluate $e_{\max }$ from $e_{\min }$ and vice versa

(3) The maximum and minimum void ratios are significantly affected by the fine content in a way that the limit void ratio decreases from $0 \%$ to $30 \%$ during the filling-of-voids phase and increases within the range of $50 \%$ to $100 \%$ in the course of the replacement-of-solids phase. Near $40 \%$ is a certain percentage showing a change of pattern indicating the transition

(4) The maximum and minimum void ratios of a given sandy soil are not unique, but rather they rest with the test methods and equipment used to determine them. Therefore, when comparing the limit void ratio of various soil, it is an essential and prerequisite condition that $e_{\max }$ or $e_{\min }$ of all soil are measured using the same test procedures. Besides, the void ratio characteristics should not be regarded as an isolated feature of the packing of sand, but rather, they should be looked upon as the fact that the particle structure is directly reflected in the mechanical properties of sand

\section{Data Availability}

The data used to support the findings of this study are available from the corresponding author upon request.

\section{Conflicts of Interest}

The authors declare that they have no known competing financial interests or personal relationships that could have appeared to influence the work reported in this paper.

\section{Acknowledgments}

This paper gets its funding from a project (Grant Nos. 51778585 and 5207080379 ) supported by the National Natural Science Foundation of China and Joint Fund of Zhejiang Natural Science Foundation Committee Power China Huadong Engineering Corporation (Grant No. LHZ19E090001).

\section{References}

[1] C.-1. Zhu, J.-x. Zhang, N. Zhou, M. Li, and Y.-b. Guo, "Permeability of sand-based cemented backfill under different stress conditions: effects of confining and axial pressures," Geofluids, vol. 2021, Article ID 6657662, 13 pages, 2021. 
[2] Z.-h. Yan, C. Cao, M.-y. Xie et al., "Pressure behavior analysis of permeability changes due to sand production in offshore loose sandstone reservoirs using boundary-element method," Geofluids, vol. 2021, Article ID 6658875, 10 pages, 2021.

[3] M. R. Coop, "The mechanics of uncemented carbonate sands," Géotechnique, vol. 40, no. 4, pp. 607-626, 1990

[4] M. R. Coop, K. K. Sorensen, T. B. Freitas, and G. Georgoutsos, "Particle breakage during shearing of a carbonate sand," Géotechnique, vol. 54, no. 3, pp. 157-163, 2004.

[5] S. Donohue, C. O’Sullivan, and M. Long, "Particle breakage during cyclic triaxial loading of a carbonate sand," Géotechnique, vol. 59, no. 5, pp. 477-482, 2009.

[6] V. Fioravante, D. Giretti, and M. J. Kowski, "Small strain stiffness of carbonate Kenya sand," Engineering Geology, vol. 161, pp. $65-80,2013$.

[7] D. Kong and J. Fonseca, "Quantification of the morphology of shelly carbonate sands using 3D images," Géotechnique, vol. 68, no. 3, pp. 249-261, 2018.

[8] Y. Wu, N. Li, X.-z. Wang, and J. Cui, "Experimental investigation on mechanical behavior and particle crushing of calcareous sand retrieved from South China Sea," Engineering Geology, vol. 280, p. 105932, 2020.

[9] Y. Qin, T. Yao, R. Wang, C.-q. Zhu, and Q.-s. Meng, "Particle breakage-based analysis of deformation law of calcareous sediments under high-pressure consolidation," Rock and Soil Mechanics, vol. 35, no. 11, pp. 3123-3128, 2014.

[10] H.-y. Chen, R. Wang, J.-g. Li, and J.-m. Zhang, "Grain shape analysis of calcareous soil," Rock and Soil Mechanics, vol. 26, no. 9, pp. 1389-1392, 2005.

[11] S.-j. Rui, Z. Guo, T.-l. Si, and Y.-j. Li, "Effect of particle shape on the liquefaction resistance of calcareous sands," Soil Dynamics and Earthquake Engineering, vol. 137, article 106302, 2020.

[12] Y.-r. Lv, X. Li, and Y. Wang, "Particle breakage of calcareous sand at high strain rates," Powder Technology, vol. 366, pp. 776-787, 2020.

[13] Y. Peng, X.-m. Ding, Y. Zhang, C.-l. Wang, and C. Y. Wang, "Evaluation of the particle breakage of calcareous sand based on the detailed probability of grain survival: an application of repeated low-energy impacts," Soil Dynamics and Earthquake Engineering, vol. 141, article 106497, 2020.

[14] L. Wang, X. Jiang, X. He et al., "Crackling noise and biocementation," Engineering Fracture Mechanics, vol. 247, article 107675, 2021.

[15] M. Oualha, S. Bibi, M. Sulaiman, and N. Zouari, "Microbially induced calcite precipitation in calcareous soils by endogenous Bacillus cereus, at high $\mathrm{pH}$ and harsh weather," Soil Dynamics and Earthquake Engineering, vol. 257, article 109965, 2020.

[16] S. T. O'Donnell and E. K. Jr, "Stiffness and dilatancy improvements in uncemented sands treated through MICP," Journal of Geotechnical and Geoenvironmental, vol. 141, article 02815004, 2015.

[17] J. D. Murff, "Pile capacity in calcareous sands: state if the art," Journal of Geotechnical Engineering, vol. 113, no. 5, pp. 490507, 1987.

[18] B. R. Danzigier, A. M. Costa, F. R. Lopes, and M. P. Pacheco, "Back analysis of offshore pile driving with an improved soil model," Géotechnique, vol. 49, no. 6, pp. 777-799, 1999.

[19] H. Jiang, R. Wang, Y.-h. Lv, and Q.-s. Meng, "Test study of model pile in calcareous sands," Rock and Soil Mechanics, vol. 31, no. 3, pp. 780-784, 2010.
[20] F. Tavenas and P. Rochelle, "Accuracy of relative density measurements," Géotechnique, vol. 22, no. 4, pp. 549-562, 1972.

[21] P. Guo, F. Liu, G. Lei et al., "Predicting response of constructed tunnel to adjacent excavation with dewatering," Geofluids, vol. 2021, Article ID 5548817, 17 pages, 2021.

[22] P. Guo, X. Gong, and Y. Wang, "Displacement and force analyses of braced structure of deep excavation considering unsymmetrical surcharge effect," Computers and Geotechnics, vol. 113, p. 103102, 2019.

[23] P. Guo, X. Gong, Y. Wang, H. Lin, and Y. Zhao, "Minimum cover depth estimation for underwater shield tunnels," Tunnelling and Underground Space Technology, vol. 115, p. 104027, 2021.

[24] GB/T 50123-2019, Standard for Soil Test Method, pp. 48-50, 2019.

[25] B. Das and K. Sobhan, Principles of Geotechnical Engineering, Cengage Learning, 2010.

[26] H. W. Humprhes, "A method for controlling compaction of granular materials," Highway Research Board Bulletin, vol. 159, pp. 41-57, 1957.

[27] Q.-g. Guo and Z.-c. Liu, "Approximation of maximum density of coarse-grained soils," Water Resources \& Water Engineering, vol. 3, no. 1, pp. 12-21, 1992.

[28] Y. Wang, C. H. Li, and J. Q. Han, "On the effect of stress amplitude on fracture and energy evolution of pre- flawed granite under uniaxial increasing-amplitude fatigue loads," Engineering Fracture Mechanics, vol. 240, p. 107366, 2020.

[29] M.-h. Fan and D.-z. Kong, "Improvement on method for relative density of sand experiments," Rock and Mineral Analysis, vol. 26, no. 5, pp. 67-68, 2007.

[30] S. Li, D.-y. Li, and Y.-g. Gao, "Determination of maximum and minimum void ratios of sands and their influence factors," Chinese Journal of Geotechnical Engineering, vol. 40, no. 3, pp. 554-561, 2018.

[31] D. C. Bobei, S. R. Lo, D. Wanatowski, C. T. Gnanendran, and M. M. Rahman, "Modified state parameter for characterizing static liquefaction of sand with fines," Canadian Geotechnical Journal, vol. 46, no. 3, pp. 281-295, 2009.

[32] C. A. Stamatopoulos, "An experimental study of the liquefaction strength of silty sands in terms of the state parameter," Soil Dynamics and Earthquake Engineering, vol. 30, no. 8, pp. 662-678, 2010.

[33] C. S. Chang and M. Meidani, "Dominant grains network and behavior of sand-silt mixtures: stress-strain modeling," International Journal for Numerical and Analytical Methods, vol. 37, no. 15, pp. 2563-2589, 2013.

[34] A. Ekinci, M. Hanafi, and P. M. V. Ferreira, "Influence of initial void ratio on critical state behaviour of poorly graded fine sands," Indian Geotechnical Journal, vol. 50, no. 5, pp. 689699, 2020.

[35] M. Cubrinovski and K. Ishihara, "Maximum and minimum void ratio characteristics of sands," Soils and Foundations, vol. 42, no. 6, pp. 65-78, 2002.

[36] X.-Z. An, "Densification of the packing structure under vibrations," International Journal of Minerals, Metallurgy, and Materials, vol. 20, no. 5, pp. 499-503, 2013.

[37] H. K. Dash, T. G. Sitharam, and B. A. Baudet, "Influence of non-plastic fines on the response of a silty sand to cyclic loading," Soils and Foundations, vol. 50, no. 5, pp. 695-704, 2010. 
[38] C. S. Chang, J. Y. Wang, and L. Ge, "Modeling of minimum void ratio for sand-silt mixtures," Engineering Geology, vol. 196, pp. 293-304, 2015.

[39] R. K. Mcgeary, "Mechanical packing of spherical particles," Journal of the American Ceramic Society, vol. 44, no. 10, pp. 513-522, 1961.

[40] B. Aberg, "Void ratio of noncohesive soils and similar materials," Journal of Geotechnical Engineering, vol. 118, no. 9, pp. 1315-1334, 1992.

[41] Y. Yilmaz, "A study on the limit void ratio characteristics of medium to fine mixed graded sands," Engineering Geology, vol. 104, no. 3-4, pp. 290-294, 2009.

[42] Y. Wang, Y. F. Yi, C. H. Li, and J. Q. Han, "Anisotropic fracture and energy characteristics of a Tibet marble exposed to multi-level constant-amplitude (MLCA) cyclic loads: a labscale testing," Engineering Fracture Mechanics, vol. 244, p. 107550, 2021.

[43] C. S. Chang and J. Y. Wang, "Maximum and minimum void ratios for sand-silt mixtures," Engineering Geology, vol. 211, pp. 7-18, 2016

[44] Y. Dong, Y. Liu, C. Hu, and B. Xu, "Coral reef geomorphology of the Spratly Islands: a simple method based on time-series of Landsat- 8 multi-band inundation maps," ISPRS Journal of Photogrammetry and Remote Sensing, vol. 157, pp. 137-154, 2019.

[45] M. Cubrinovski and K. Ishihara, "Empirical correlation between SPT_N-_value and relative density for sandy soils," Soils and Foundations, vol. 39, no. 5, pp. 61-71, 1999.

[46] M. R. Muszynaki, "Determination of maximum and minimum density of poorly graded sands using a simplified method," Geotechnical Testing Journal, vol. 29, no. 3, pp. 263-272, 2006.

[47] A. Papadopoulou and T. Tika, "The effect of fines on critical state and liquefaction resistance characteristics of non-plastic silty sands," Soils and Foundations, vol. 48, no. 5, pp. 713725, 2008. 